\title{
Tetraamelia-multiple malformations syndrome
}

INSERM

\section{Source}

INSERM. (1999). Orphanet: an online rare disease and orphan drug data base.

Tetraamelia-multiple malformations syndrome. ORPHA:3301

Tetraamelia - multiple malformations is an extremely rare mostly lethal congenital disorder characterized by absence of all four limbs and frequent associated major malformations involving the head, face, eyes, skeleton, heart, lungs, anus, urogenital, and central nervous systems. The syndrome has been described in fewer than 20 patients mainly of middle Eastern descent. 